\title{
Bir Sergileme Yöntemi Olarak Artırılmış Gerçeklik
}

Arş. Gör. Cumhur Coşkun

\section{Özet}

Bir sergileme yöntemi olarak artırılmış gerçeklik son dönemde yapılan özellikle yeni sanat akımları ve sanatsal etkinliklerde kullanılmaktadır. Artırılmış gerçeklik, teknolojinin insan hayatındaki yeri ve etkinliğinin arttığını ve bunun da her alanı açıkça geliştirmekte ve yenilemekte olduğunu göstermektedir. Artırılmış gerçekliği kullanarak akıllı cihazlar aracilığıla iki boyutlu görselleri ya da sergide yer alan unsurları hareketli ya da kısa bir animasyonla zenginleștirmek ve video ekleyerek ve ilgi çekici bir deneyim sunmak mümkün olabilmektedir. Teknolojinin tüm olanaklarının farkındalık ve ilgi çekici bir deneyim sunmak mümkun olabilmektedir. Teknolojinin tüm olanaklarının farkındalık içinde kullanılması ile tasarımcıların ve sanatçıların yaratıcı sınırlarını genişletmelerine de olanak
sağlamaktadır. Bunun gibi avantajlarıyla artııılmış gerçeklik bir sergileme yöntemi olarak her geçen gün sanat etkinlikleri ve sergilerin de tercih edilerek kullanılmaktadır. Bunun yanında artırılmış gerçeklikle olusturulan sergiler fazla vakit alabilir ve fazla dikkat dağıtıı da olabilmektedir. Yapılan bu çalş̧mada artırılmış gerçekliğin özellikle kişisel sergiler ve tarih müzelerinde kullanılmış örnekler ele alınarak sergileme yönteminde etkileri incelenerek artırılmış gerçekliğin bu alanlardaki katkısı nitel verilerle desteklenerek araștırlacaktır.

Anahtar Sözcükler: Sergileme Yöntemleri, Artırımış Gerçeklik, Akıllı Cihazlar

\section{AUGMENTED REALITY AS A METHOD OF EXHIBITION}

\section{Abstract}

Augmented reality as a method of exhibition is used especially in new artistic trends and artistic events in the recent period. Augmented reality shows that technology has increased the place and effectiveness of human life, which clearly shows that every field is evolving and renewing. Using augmented reality, it is possible to enrich two-dimensional visuals or elements of the exhibition with animated or short animations via smart devices, adding video and providing an engaging experience. And also the awareness of all the possibilities of technology allows artists and designers to broaden their creative boundaries. Augmented reality with the advantages like this is being used as a method their creative boundaries. Augmented reality with the advantages like this is being used as a method
of exhibition every day by preferring art events and exhibitions. Besides, exhibitions created with augmented reality can take more time and become more distracting. In this article, it will investigate the effects of the augmented reality in the exhibition method, especially the examples used in personal exhibitions and historical museums, and investigate the contribution of the augmented reality to these fields with positive and negative aspects supported by qualitative data.

Keywords: Augmented Reality, Exhibition Methods, Smart Devices 


\section{Giriş}

70'li yılların sonlarından itibaren hayatımıza giren dijital ortamlar sanatta köklü değişiklikler yaratmışlardır. Çığ gibi büyüyerek her geçen gün daha fazla alana yayılan teknoloji hayatımızı şekillendirmeye devam etmektedir. “1980'li yıllardan itibaren yoğun bir şekilde hayatı etkilemekte olan dijital dönem bir yandan yeni algılama biçimleri üretmekte, bir yandan da, gerek var olan, gerek de türemekte evirilmekte olan söz konusu algılama biçimlerinin ifadesinde yeni olanaklar getirmektedir." (Michael, 1998: 34).

Veriler sanal ortamda yeniden şekillendirilip sınırlı olarak algıladığımız gerçekliği ayrıntılı algılama fırsatları sunmaktadır. Teknoloji hayatımızı her açıdan şekillendirmekte ve yeniden kurgulamaktadır. Somut olarak fiziki açıdan var olan biçimler sanal ortamda yeniden şekillenme olanağı bulmaktadır.

Teknoloji devriminin insanoğluna getirdiği yeni durumda algısal süreçlerin farklılaşması, düşünce ve eylem kalıplarının değişmesi, esnekliklerin artması; gerek fikir üretiminde gerekse bunların uygulanmasında yepyeni olanaklar getirmektedir. Bilgi ve teknoloji çă̆ı sanatı bu yeni oluşumların içine çekmekte sanata yeni kapılar açmaktadır. Bu açıdan sanat bu oluşumun içinde, öncü misyonuyla merkezde olmaya devam etmektedir.

Teknoloji sanatın içinde kendine bir yer edinerek her açıdan sanatı etkilemekte ve şekillendirmektedir. Düşünce ve eylemleri farklı şekilde sunulmasında, sanatın teknoloji ile harmanlanarak yeni sanat biçimleri geliştirilmesi gibi birçok açıdan sanat teknoloji birlikteliği görülmektedir.

Bu birliktelik özellikle, teknolojik değişimler ve teknolojiye karşı oluşan eğilimler birçok alanda olduğu gibi sergileme yöntemlerinde de yenilikçi yaklaşımların ortaya çıkmasını sağlamıştır. Artırılmış gerçeklikte bu yeni yöntemler arasında görülmektedir.

Interaktif sanat etkinlikleri sanata daha dinamik bir hava katmıştır. Sanat ve insan arasındaki etkileşime yeni bir boyut getirmiştir. Bu ilişki ile yapıt bir bireysel deneyim ve yaşantı ortamına dönüşmektedir.

Artırılmış gerçeklik, sanal karakter ve unsurları gerçek dünya ile bir araya getirmektedir. Nesne algılama teknolojilerinin desteği ile kullanıcının çevresindeki dünya ile ilgili bilgi verir ve etkileşimli biçime getirir. Etkileşimli unsurlar bireylerde daha aktif bir tutum geliştirdiği için sergideki o pasif izlenimciyi aktif hale getirerek daha etkili bir sergiye dönüştürebilir.

Artırımış gerçeklik ile oluşturulan sergiler de; gerçek dünyanın kamera ile görüntüsünün alınması sırasında, gerçek dünya üzerinde önceden belirlenmiş olan hedef noktalara, bilgisayarda yaratılmış olan materyallerin belli noktalarından bağlanması ve oluşan sonucun programlar vasıtasıyla yorumlanarak çıktı görüntünün eş zamanlı olarak alınmasıdır.

Bir sergiyi görsel bir izlenimden öteye taşıyan artırılmış gerçeklikle hem sergilenen eser daha fazla ilgi çekmekte hem de daha etkili bir hale gelebilmektedir. Böylece bir serginin görünenden daha fazlasını sunmasında artırılmış gerçeklik büyük rol oynamaktadır.

\section{Artırılmış Gerçeklik}

Artırılmış gerçeklik, gerçek bir mekân veya objenin üzerine sanal bir bileşenin bindirilmesi ile oluşmaktadır (Azuma, 2001).

Artırılmış gerçeklikteki amaç; fiziki gerçeklik algısıyla elde edilen bilgiye sayısal bir bilgi eklemesi yapmaktır. Böylece kullanıcının algısının kuvvetlendirilerek hedef mekân, yapı ya da obje ile alakalı daha fazla bilgiye sahip olması hedeflenmektedir.

Yine artııılmış gerçeklik, gerçek dünyayı dijital olarak zenginleştiren, günlük yaşamınızda daha anlamlı içerikler barındıran en yeni teknolojilerden biridir. Bir Akıllı Telefon veya tabletteki kamera ve sensörlerle artırılmış gerçeklik, çevremizdeki dünyadaki ürünlerin üstünde doğrudan video, fotoğraf ve ses biçiminde dijital bilgi katmanları eklemektedir (Mathew, 2014).

Gelişen teknoloji neticesinde, artırılmış gerçeklik uygulamaları daha ulaşılabilir ve geliştirilebilir olmuştur. Akıllı telefon ve tabletlere indirilen uygulamalar sayesinde artırılmış gerçeklik ile oluşturulan veriler yani ses, grafik, yazı, görüntü gibietkileşimliunsurlargörüntülenebilmektedirveayrıca eğitim, tıp gibi daha önemli alanlarda da etkin olarak kullanılabilmektedir.

Çeşitli alanlarda kullanılmaya başlayan artııımış gerçeklik uygulamaları ile araştırmacılar tarafından tıp, eğlence, eğitim, mühendislik sanat gibi birçok alanda artııımış gerçeklik uygulamalarının protipini geliştirmişlerdir. Örneğin, doktorlar hastanın vücudundaki tıbbi verileri göstermek için (Navab, Feuerstein ve Bichlmeier, 2007), Oyun oynayanlar sanal canavarlarla gerçek dünyada savaşabilmek için (Piekarski ve Thomas, 2002), mimarlar bitmemiş binalarının kısımlarını görebilmek için (Thomas, Pinz, 1999) ve öğrenciler gerçek dünyada sanal molekülleri bir araya getirebilmek için bir dizi bunun gibi uygulamalar geliştirilmiştir (Billinghurst, Clark ve Lee, 2015: 3) (Görsel 1). 


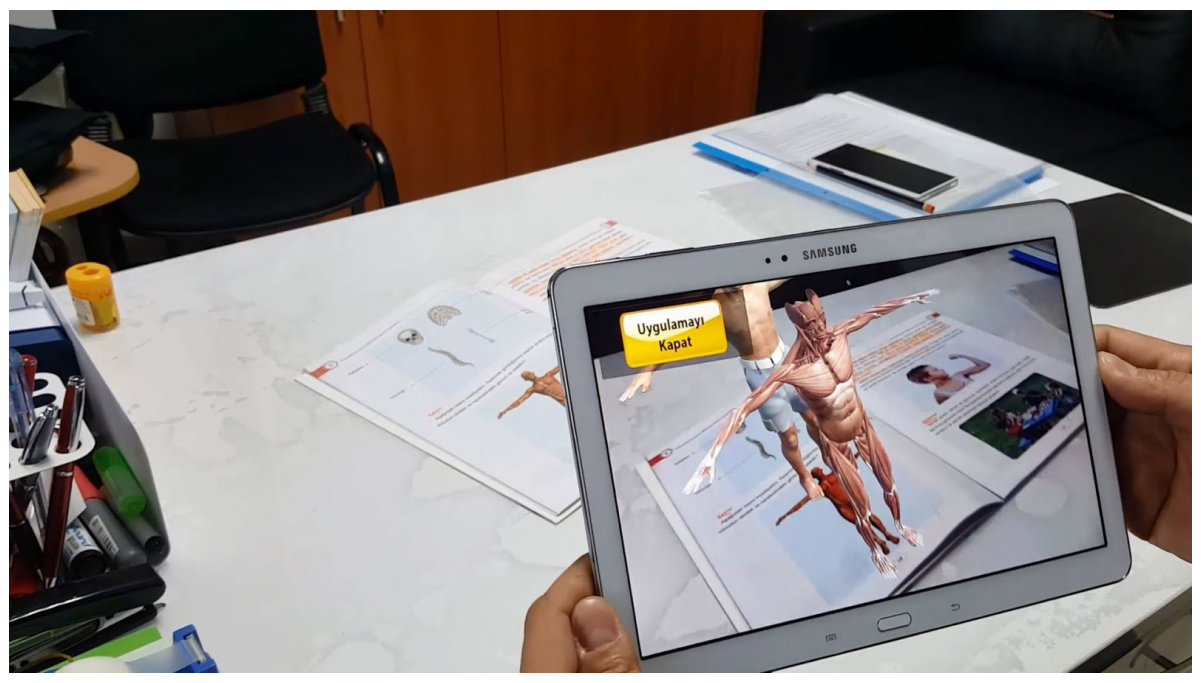

Görsel I. TIp Alanında Artırılmış Gerçeklik

Bunun yanı sıra artııılmış gerçeklik ve sanal gerçeklik karışıııılmaktadır. Sanal gerçeklik sanal ortamda gerçek ortamın yeniden oluşturulmasıdır. Oysaki artırımış gerçeklik var olan gerçek ortama ek olarak yeni görüntü ses ve biçimler katarak oluşturulmaktadır (Görsel 2).
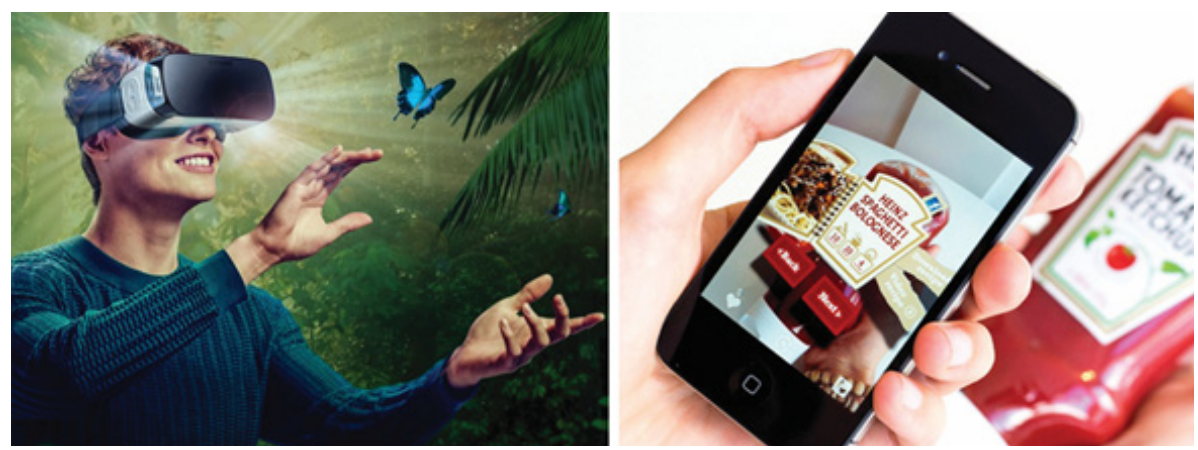

Görsel 2. Sanal Gerçeklik ve Artırılmış Gerçeklik

Artııımış gerçeklik ve sanal gerçeklik, ayırt edici çizginin bulanıklaştığı alanlardır. Başka bir deyişle, sanal gerçekliği artırılmış gerçekliğin öncüsü olarak düşünebilirsiniz; bazı parçalar her ikisinde birden örtüşür. íki teknoloji arasındaki en büyük fark, sanal gerçekliğin kamera yayını kullanmamasıdır. Sanal gerçeklikte gösterilen her şey ya animasyonlar ya da önceden kaydedilmiş film parçalarıdır (Sood, 2012: 1).

ARART, sanatsal çalışmaların, artııımış gerçeklik platformlarını kullanarak gerçek dünyada farklışekillerde görüntülenmesinisağlayan bir uygulamadır. Bu uygulamada, dünyaca ünlü sanat eserleri hareketlendirilebilmekte, modern tasarımlar farklı tasarımlara dönüsebilmekte, eserlerin ses, animasyon veya video eklenmiş halleri görüntülenebilmektedir (Görsel 3).

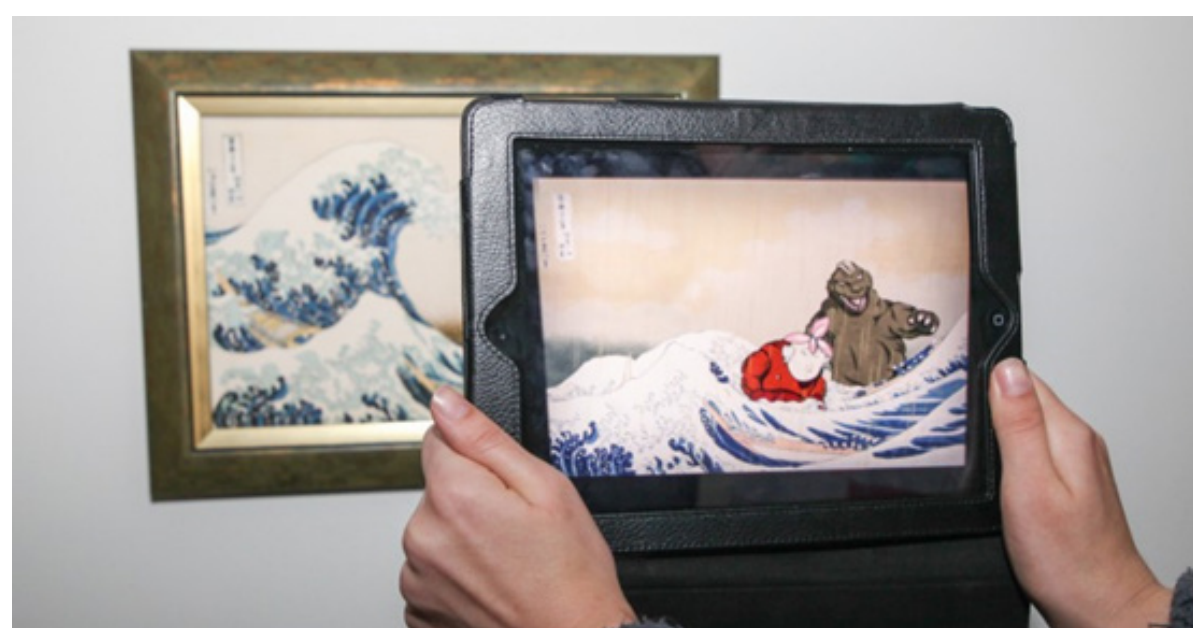

Görsel 3. ARART Uygulaması ile Oluşturulmuş Bir Sergiden

ARART uygulaması ile fiziksel arka planın kamera ekranına yansıyan görüntüsü üzerine eklenerek oluşturulan yeni görünümleridir. Yine genişletilmiş bir biçimde anlaşılmasını destekleyen görüntünün, mobil ekrandaki ek bilgilerle aynı anda üzerine yerleştirilerek oluşturulur.

Mobil artııımış gerçeklik uygulamalarının ücretsiz ve kolay ulaşılabilir olması artan ilgiyle bu alandaki araştırmaların artmasında önemli bir unsur olarak bahsedilebilir. Bu uygulamalar ile poster gibi 2 boyutlu görseller video eklenerek hareketli unsurlarla daha ilgi çekici hale getirmek mümkün olmaktadır. Özellikle artırılmıs gerçeklik uygulamalarıyla mümkün olan sınırlı etkileşimin ötesine geçilebilmektedir

Artırımış gerçeklik teknolojisi, en azından şu andan itibaren gerçek donanımın yapamadığı şeyleri yapabilir. Bir küp gibi olağan bir nesneye sahip olduğunuz bir ekrana sahip olabilirsiniz. Daha sonra bu küpe çesitli senaryolar ve kuvvetler uygulayıp nasıl çıktığını görebilirsiniz. Bunu gerçek donanımla yapamazsınız, çünkü gerçek donanım genellikle bozulmadan sekli değiştiremez. Ayrıca son derece pahalı veya tamamen imkânsız olacak teorileri, deneyler kullanarak test edebilirsiniz (Sood, 2012: 10).

Artırımış gerçeklik teknolojisi ile var olan sorunları deneme yanılma gibi yöntemlerle test etme imkânı da sunması bilime getirdiği artılar arasında 
gösterilmektedir. Daha pek çok alanda denemeler yapma test etme gibi olanaklar sunması önemlidir.

Artırımış gerçeklikte bir kullanıı tarafından deneyimlenen ortam gerçektir (sanal olmanın aksine), bu ortam, bir bilgisayar sistemindeki bilgi ve görüntüleri içerecek şekilde genişletilir. Başka bir deyişle, artırılmış gerçeklik sanal ve gerçek dünya arasında bir bağlantı oluşturarak gelişmiş bir deneyim yaratabilir ( Djamasbi, Wyatt, Luan \& Wang, 2014: 3).

Bir yanılsama yaratmayı amaçlayan artııılmıs gerçeklik sanal görüntüler ve gerçek dünya ile kesintisiz bir şekilde harmanlanmaktadır. Artırılmış gerçeklik insan bilgisayar etkileşim teknolojisindeki en büyük gelişmelerden biridir.

\section{Bir Sergileme Yöntemi Olarak Artırılmış Gerçeklik ile Oluşturulan} Sergiler

Sergiler, sanat eserleri gibi, hiçbir yerde ortaya çıkmamışır. Belli anlarda, kendi tarihsel koşullar kümeleri altında görünmüşlerdir. Sanat tarihçisi TJ. Clark 1973 tarihli "İnsanın İmajı" kitabının açılış bölümünde, "En iyi biçimde sanat tarihi, sanatsal biçim, mevcut görsel sunum sistemleri, mevcut sanat teorileri, diğer ideolojiler, sosyal sınıflar ve daha genel tarihsel yapılar ve süreçler arasındaki bağlar hakkında olmalıdır" diye belirtmiştir. Bu aynı zamanda sergilerin kendilerinin ne olduğunun mükemmel bir özeti ve sergilerin bir geçmişi gerçekleştirmesini amaçlamasıdır (Hoffmann, 2014: 13).

1990'Iı yılların başlarından bu yana sergi açma ve küratörlük dramatik bir değişim geçirdi. Müzelerin koleksiyonlarında yer alan nesnelerin korunması, yorumlanması ve sergilenmesiyle ilgili uygulamalardan gerçekten yaratıcı meslekler haline geldi. Küratörler, gösterdikleri temel fikirlere giderek kendi öznelliklerini yerleştiriyorlar ve sunumların kendileri formda ve içerikte her zaman değişiyor. Bunun sonucunda ise bazı unutulmaz ve ilham verici sergiler ortaya çıktı (Hoffmann, 2014: 11).

Sanateserleri kendizamanında ve kendişartları altında izleyicisine ulaşmıştır. Zaman sanatın şeklini ve oluşumunu nasıl değiştirdi ise sergilenmesi üzerinde de belirgin farklılıklar göstermiştir. Artık sanat kapalı duvarlar ardından çıkarak her an her yerde kendini izleyicisine sunmaktadır.

Sergiler de zamanla yeni sergileme yöntemleri ile yeni anlatım biçimleri geliştirmekte sanatçıya yeni ufuklar açarak daha zengin bir yelpaze de izleyiciyle buluşmaktadır. Bir sergileme yöntemi olarak artııımış gerçeklik sanatçıya fiziki gerçeklik dışında izleyicinin daha çok dikkatini çekerek farklı bir deneyim de sunmaktadır.

Dünyada sayısız müze ve sanat galerisi olduğu bilinmektedir. Geçmişten günümüze bu müze ve galerilerde çeşitli sergileme yöntemlerini görmekteyiz. Son dönemlerde özellikle teknolojinin de getirisiyle bu alanlarda sergilemeye ek olarak video artlar etkileşimli uygulamalarında ziyaretçilerin ilgisini çekmektedir. Yine teknoloji sayesinde sanal gerçeklik uygulamalarıla gitmeden evden bu müze ve galerileri gezmek mümkün olmaktadır.

Artııımış gerçeklik uygulamalarııı sergileme yöntemlerine etkisinden bahsetmeden önce sanal gezintilerin etkisinden bahsetmek gerekmektedir. Sergilerdeki sanal gezinti ortamları sergide yer alan eserlerin 3 boyutlu olarak yeniden sanal ortamda yaratılan görüntülerinin gösterildiği etkileşimli uygulamaların yer aldığı ekranlar ile sergiler daha etkili olma yolunda teknoloji ile her geçen gün zenginleşmektedir. Sergilerdeki bu uygulamalar ile müze ziyaretçileri görselleştirilmiş etkileşimli koleksiyonlar arasında gezinmek, müze galerilerindeki bu zenginleştirilmiş ortamlarda elde edilen deneyimlerden keyif almaktadırlar.

Artııımış gerçeklik sergilere ulaşmak daha zor olmasına rağmen, Web3D ve sanal gerçeklik sergilerine kıyasla müze ziyaretçilerine daha fazla avantajlar sunmaktadırlar. Spesifik olarak, bir artııımış gerçeklik müzesinde, sanal bilgiler (genellikle 3B objeler, metinsel veya imgesel bilgileri içeren multimedya türleri de olmak üzere), kamera tarafından kaydedilmiş video kareleri, kullanıcıya sanal kültürel nesnelerin gerçek ortamda var oldukları etkisi oluşturmaktadır (Styliani, Liarokapis, Kostas \& Petros, 2009: 523).

Insan bilgisayar etkileşim teknikleri sayesinde, kullanıcılar sanal objeleri, dokunulabilir manipülasyon bileşenleri veya sensörler aracilığıyla tamamen inceleyebilmektedir. Bu "artııııış" gerçek-dünya ortamı, müze bilgilerine sezgisel erişime rehberlike debileceği gibi, müze sergilerinin sanal ziyaretçiler üzerindeki etkisini de artırabilmektedir (Styliani vd., 2009: 523).

Insan bilgisayarın verdiği etkileşim tecrübesi sayesinde sanal ortamda objelere dokunabilir daha ayrıntılı inceleyerek daha fazla deneyim elde edebilmektedir. Bu artııılmış gerçeklik sayesinde gözüyle gördüğü sanat objesini artırılmış gerçeklik ile tablet veya akıllı telefon vasıtasıyla ekranda onun 3 boyutlu versiyonu üzerinde daha fazla etkileşim kurma imkânı bulmaktadır (Görsel 4). 


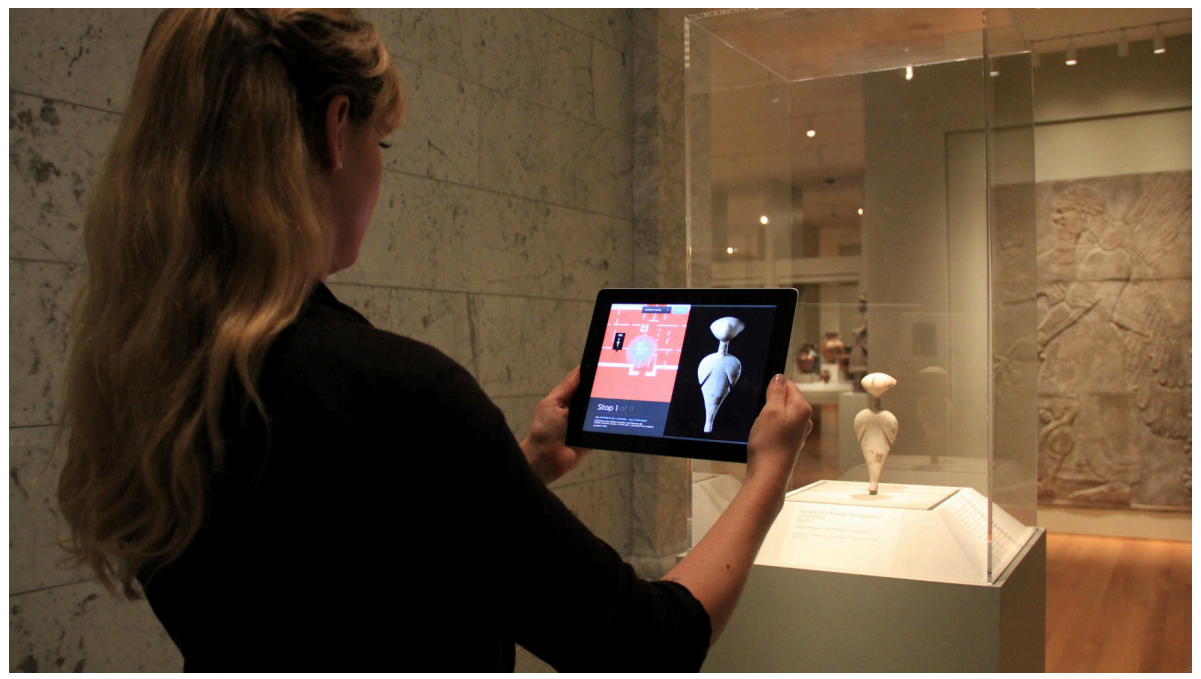

Görsel 4. Artırılmış Gerçeklik Uygulaması ile Müze Deneyimi

Artırılmıs gerçeklik müze sergileme sistemleri günümüzde farklı uygulama yöntemleri ve sunum teknikleri ile en çok rağbet gören sistemlerdir. Ülkemizde gün geçtikçe sayısı artan uygulama örneklerinden birisi Çorum Arkeoloji Müzesi tarafından da uygulanmaktadır. Müze için 'Savaş Arabası Simülatörü' uygulamasıyla Hattuşaş Antik Kenti'nde gezi, 'Ölü Gömme Töreni' ile tunç çağı objelerinin ve yerleşiminin incelenmesi ve '3 Boyutlu Vazo İnceleme' uygulamaları, müze içinde etkileşimli uygulamalara birer örnek teşkil etmektedir.

Teknolojinin müze ve sergilerde yer alması sergileme yöntemlerine faydalı birer eklenti olarak düşünülmüştür. Bu teknolojik uygulamalar, geleneksel müze ve sergi deneyimlerine birer ek ve cazibe kattığı düşünülmektedir.

\section{The Danger Tree Artırılmış Gerçeklik Sergisi}

Scarlett Raven, 2016 yılında Washington Green Fine Art galerisinde açtığı sergide bir sergileme yöntemi olarak artırılmış gerçekliği kullanmıştır. Artırılmış gerçeklik ile çalışan ilk yağlı boya sanatçılarındandır. Bu sanatçı çok katmanlı, deneyimsel sanatı yaratma sürecini kişisel olarak ortaya koymuştur. Blippar uygulaması ile birlikte artııımış gerçekliği kullanan bir sanatçıdır. İzleyiciler sanatçının eserlerini izlerken akıllı telefonlarında yer alan bu uygulama ile eserlerin kilidini açarak yeni bir deneyim elde etmektedirler.

Bu sergi dünyanın ilk artırılmış gerçeklik sergisidir. Sanatçı artırılmış gerçeklikle yaptığı eserin katmanlarını göstermeyi ve izleyicinin süreci daha gerçekçi bir şekilde canlı olarak görmesini istemektedir. Sanatçı artırılmış gerçeklikle eser ile yaşadığı süreci izleyiciyle buluşturmak isterken, bir eserin tamamlanmadan önce nasıl bir süreçten geçtiğini göstererek izleyiciyi eserle olan o kısa bakışta daha fazla kalması için etkili bir yol olarak görmüştür (Görsel 5).

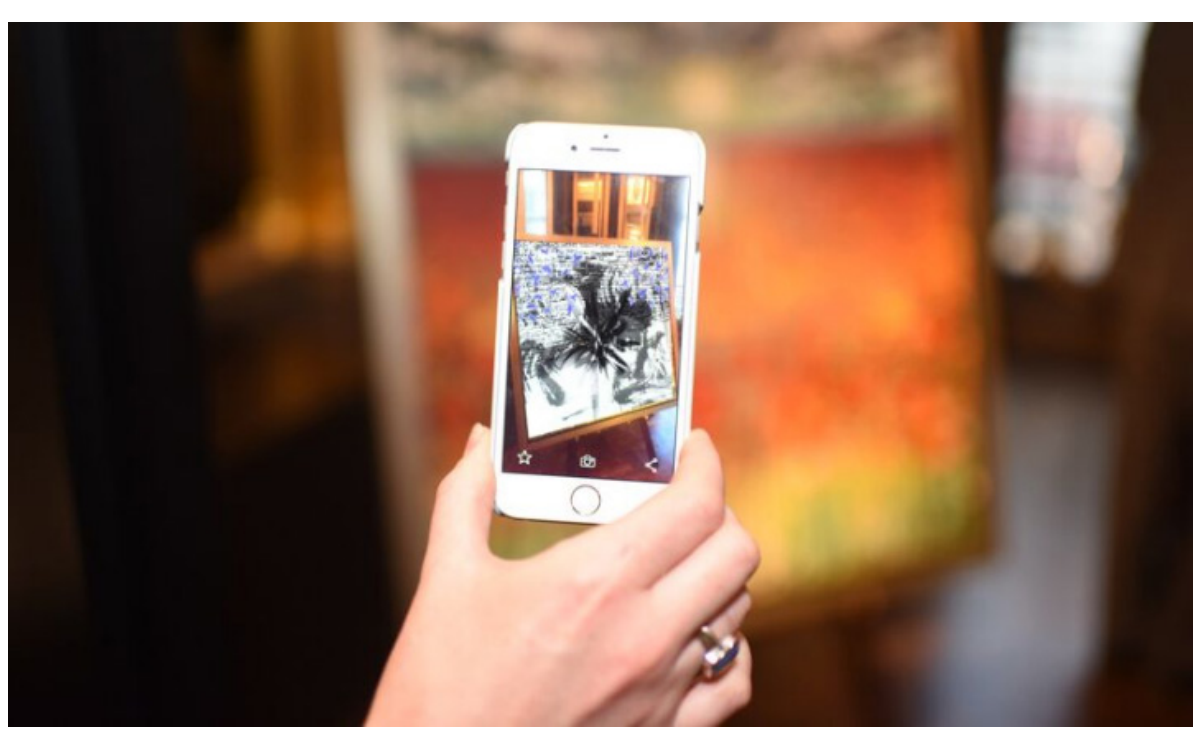

Görsel 5. The Danger Tree Sergisi

\section{Priya's Shakti}

Mahendra Parshuram Vartak, Niren Vashram Savaniya ve Sham Maruti Jadhav hazırladıkları hikâye projesi kapsamında sergilemede artııımış gerçeklik uygulamasını kullanmıstır. Ölümlü Bir kadın ve Tanrıça olan Parvati Hindistan'da toplumsal cinsiyet temelli cinsel şiddete karşı savaşmaktadır. Sanatçılar bu hikâyede İzleyicileri tamamen interaktif uygulamalar ve artııımış gerçeklikle izleyicisini dinamik karakter ve konuşmalarla daha gerçekçi bir hikâye anlatmak istemektedir.

Hikâyedeyer alan tüm resimler ücretsiz bir uygulama olan Blippar aracılı̆̆ıyla görülen artııımış gerçeklik unsurlarıyla donatılmışlardır. İzleyiciler, Blippar ile hikâyenin sayfalarını akıllı telefonlarında taradıklarında, özel animasyonu ve filmleri duvardan dışarıya çıkarıp görülebilmektedir (Görsel 6). 


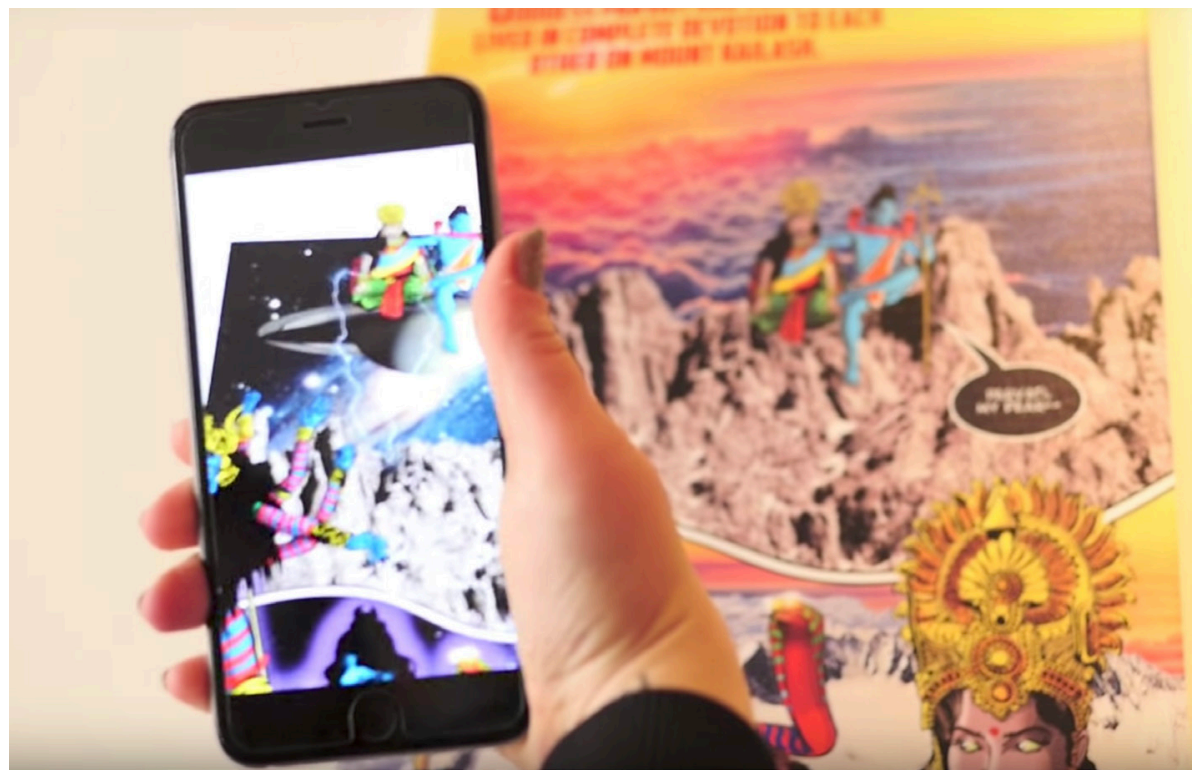

Görsel 6. Priya's Shakti Sergisi

Hindistan'da çeşitli dini inanışlar mevcuttur bunların içinde en yaygın olanlardan biri de Hinduizmdir ve ikonografisi daima her yerde bulunmaktadır. Tanrıça Durga'nın bir kaplanın önündeki görüntüsü, evler, işyerleri ve ibadet yerlerinde rahatlıkla görülebilmektedir. Priya, tecavüzden kurtulmuş bir adam ve de değişimin katalizörüdür. Artırılmış gerçeklik aracılığıyla görüntüler hareket ederek hikâye canlandırılıyor ve bununla amaçlanan, Priya'nın kaplan üzerindeki imajııı toplumsal cinsiyete dayalı şiddetle mücadele için güçlü bir simge haline getirmektir.

\section{Proshetic Reality}

Akıllı telefon ve tabletler gün geçtikçe daha fazla hayatımızda yer edinmekte ve onlara ayırdığımız vakit her geçen gün artmaktadır. Bu akıllı cihazlar ile de bir çok uygulama hayatımıza girmektedir. Özellikle geliştirilen gerçekçi oyunlar yaş sınırı olmaksızın büyük bir çoğunluğu etkisi altına almaktadır. Artık kitap gazete okuma gibi eylemler basılı yayından ziyade akıllı telefon ve tabletlerde yapılarak daha etkileşimli ve etkili olmaktadır. Sanatçı Stu Campbell, artırılmış gerçeklikle oluşturduğu çizgi romanı "Modern Polaxis" te hikâye anlatım aracı olarak kullanılmasını araştırmıștır. Campbell, "Şu anda, animasyonlu içeriği görmek için telefonunuzu bir kitap üzerinde sallayarak tuhaf bir deneyim yaşıyorsunuz" diyerek artııımış gerçeklik ile ilgili düš̈nncelerini dile getirmiştir. "Gelecekte giyilebilir (Artırılmış gerçeklik gözlüğü) olacağız ve Artırılmış gerçeklik içeriğini tüketme deneyimimiz kesintisiz bir hale gelecektir. Yeni giyilebilir teknoloji düştüğünde, çizme için artırılmış gerçeklik ürünlerinin bolluğuyla ve sağlam bir sanatçı ağıyla uyumlu olmayı istiyoruz “" demiş̧ir (Görsel 7).

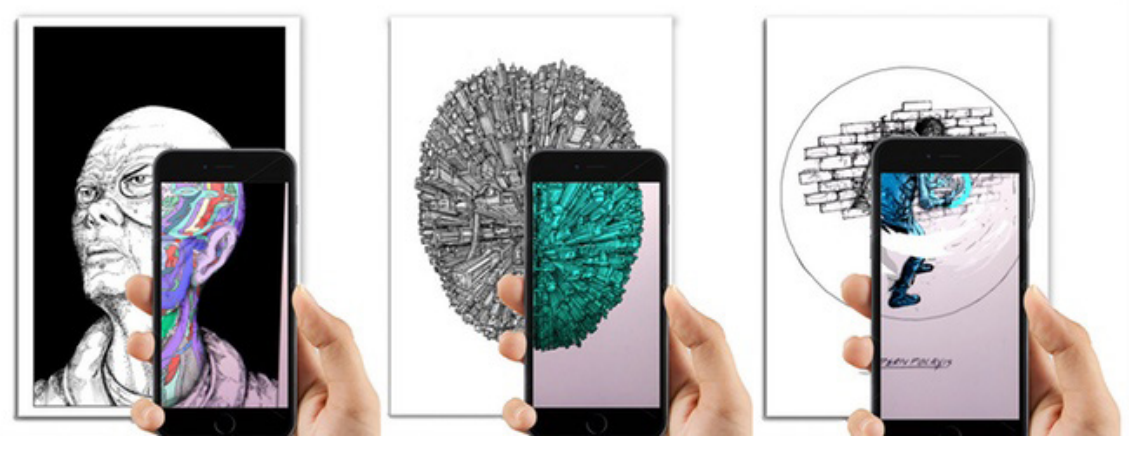

Görsel 7. Stu Campbell'in Çizgi Roman Sergisinden

\section{MOMA Conflux Festivali}

New York'ta yer alan Modern Sanatlar Müzesi (MoMA) çağdaş sanatçıarın eserlerinin sergilendiği önemli merkezlerdendir. Sanatçılar ve küratörler Sander Veenhof ve Mark Skwarek, "kentin kamusal alanının yaratıcı araştırıması için sanat ve teknolojiye" adanmış bir NYC festivali olan Conflux Festivali kapsamında MoMA'da DIY Artııımış Gerçeklik Sanat Varlığını düzenlemişlerdir. Artırılmış gerçeklik uygulaması olan Layar' I iPhone veya android telefonuna sahip olan herkes, MoMA' nın sergi galerileri ve bahçesi arasında dağılııs olan artırılmış gerçeklik çalışmalarının kullanışlı bir haritasını ile gizli sergiyi görebilmektedir (Görsel 8).

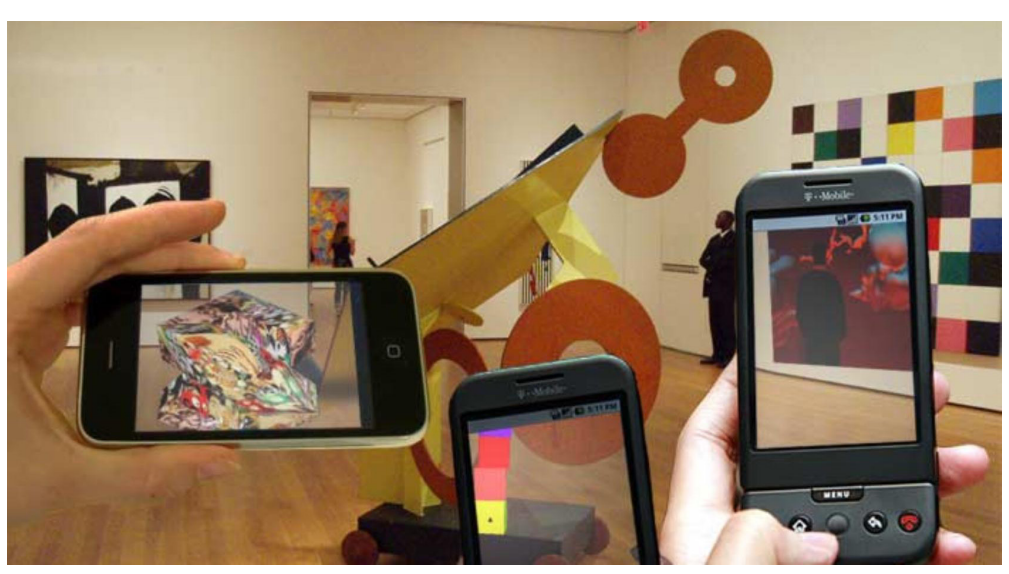

Görsel 8. Moma Artırılmış Gerçeklik Sergisinden 
Artırımış gerçekliğin fiziksel gerçekliğimize sanal unsurlar ekleyen olgulardan olduğunu belirten Veenhoof ve Skwarek (2010) "yine artırılmış gerçeklik teknolojisi ile herkesin herhangi bir yerden (yeniden) şekil vermesine olanak tanıdığını belirtmişlerdir".

\section{Sonuç}

Artırımış gerçeklik teknolojisi günden güne kullanım alanları artan, ilgi gören ve gelişmekte olan bir alandır. 3 boyutlu teknolojilerin mobil aygıtlar ve uygulamalarıyla beraber kullanılması ve bu teknolojiyle doğru orantıda ilerlemesiyle artııımış gerçekliği yeni medya alanı içinde de tanımlamak mümkün olabilmektedir. Yaşamımızın daimi bir parçası haline gelen mobil aygıtlarla AG'nin sıkça kullanılması ise bu teknolojiye ulaşımı ve ilgiyi de artırmaktadır.

Günden güne ilerleyen ve bir çok alanı da kapsamaya başlayan bu teknolojinin sanat ve tasarım alanlarılla yoğun ilişkisini de görmek mümkün olabilmektedir. Bir sergileme yöntemi olarak artırılmış gerçeklik de bu ilişkinin bir örneğidir.

Sanatçılar, küratörler ve müzeler artırımış gerçeklik teknolojisini kullanarak kendi sanat anlayışları içerisinde farklı ifade biçimlerini ortaya koyabilmektedirler. Örneğin bir sanatçı izleyicilerinin yalnızca bitmiş bir esere değil aynı zamanda tamamlanmış bir resimdeki düşünce süreçlerini katmanlarını da sanatçıyla beraber deneyimlemesi için artııılmış gerçeklik teknolojisini kullanmıştır. Başka bir sanatçı artııııış gerçeklik teknolojisini toplumsal cinsiyete dayalı şiddetle mücadele için güçlü bir simge haline getirmek için kullanıyor. Bir diğer sanatçı ise artırılmış gerçeklik kitabı oluşturarak fiziksel baskılı bir eseri anlamlı hale dönüştüren ve daha fazla şey katan yeni bir animasyonlu dijital sanat katmanına dönüştürmek için kullanıyor. Müzeler ise kendilerine olan ilgiyi artırmak koleksiyonlarında bulunan fakat başka sergileme alanlarında bulunan eserleri müze içerisinde tekrar canlandırmak için kullanabilmektedirler.

Görüldüğü üzere artırılmış gerçeklik teknolojisi, sanatın içerisinde farklı ortamlarda, farklı iletişim biçimleri şeklinde kendine yer bulmaktadır. Belki bu ifade biçimleri değişecektir, fakat teknolojinin ilerlemesiyle yerini daha da sağlamlaştırıp sanat ve tasarım alanlarında yer almaya devam edecektir. 


\section{Kaynakça}

Azuma, Ronald T. (200I), Augmented Reality: Approaches and Technical Challenges. Woodrow Barfield and Thomas Caudell, editors. Malibu,CA: Lawrence Erlbaum Associates, Chapter 2, pp. 27-63.

Billinghurst, M., Clark, A. \& Lee, G. (2015). A Survey of Augmented Reality. Foundations and Trends ib Human Computer Interaction, 8(2-4), 75-273.

Djamasbi, S., Wyatt, J. Luan, X., and Wang, H. (20/4). Augmented Reality and Print Communication. Americas Conference on Information Systems (AMCIS), Savannah, Georgia, I-9.

Hoffman, J. (2014). Show Time: The Most Influential Exhibitions of Contemparary Art. London: Thames \& Hudson Ltd.

Mathew, P.R. (2014). The Use of Augmented Reality Media- A Case Study on The "Alive" Application by Times of India.

Michael, H. (1998). Virtual Reality and Tea Ceremony. The New York Magazine, September II, I-27.

Navab N., Feuerstein M., and Bichlmeier C. (2007). "Laparoscopic virtual mirror new interaction paradigm for monitor based augmented reality”, In Virtual Reality Conference, VR'07. IEEE, 43-50.

Sood, R. (20I2). Pro android Augmented Reality. New York: Apress.

Styliani, S., Liarokapis F., Kostas L., Petros P. (2009), "Virtual museums, a survey and some issues for consideration", Journal of Cultural Heritage, 10 (2009), Bildiriler, 520-528.

Thomas A. and Pinz A. (1999). Building a hybrid tracking system: Integration of optical and magnetic tracking. In Augmented Reality, (IWAR'99) Proceedings. 2nd IEEE and ACM International Workshop on, 13-22.

Veenhof, S and Skwarek, M. (2010, 10 October) Interwiev About Augmented Reality Exhibition In MOMA. Museum OfModern Art, New York.

\section{Görsel Kaynakları}

Görsel I. Tıp alanında artırılmış gerçeklik, http://kodyazar.net/tr/egitimde-sanalgerceklik-artirilmis-gerceklik 2 Haziran 20I7'de alınmıştır.

Görsel 2. Sanal gerçeklik ve artırılmış gerçeklik, http://www.endustri40.com/artirilmis- gerceklik-augmented-reality 2 Haziran 2017'de alınmıștır.

Görsel 3. http://file.org.br/interactive_installation/takeshi-mukai-kei-shiratori-younghyobak-arart I5 Mayıs 2017'de alınmıștır.

Görsel 4. http://www.augmentedrealitytrends.com 12 Mayıs 2017'de alınmıştır.

Görsel 5. http://www.digitalmeetsculture.net/article/the-danger-tree-worlds-firstaugmented-reality-fine-art-exhibition 10 Haziran 2017'de alınmıştır.

Görsel 6. https://blippar.com/tr/galeri/\#priyas-shakti 3 Haziran 2017'de alınmıştır.

Görsel 7. https://www.cnet.com/news/prosthetic-reality-the-artification-of-augmentedreality 3 Haziran 2017'de alınmıştır.

Görsel 8. (https://creators.vice.com/en_au/article/augmented-reality-art-takes-over-themoma 24 Mayıs 2017'de alınmıştır.

\section{Internet Kaynakları}

Internet: Stu Campbell's Modern Polaxis Comic Book, https://news.artnet.com/art-world/ scarlett-raven-interview-555824 adresinden 2 haziran 20I 7'de alınmıștır. 